\title{
Evaluating Race and Oral Health in the Four Largest States in United States of America
}

\author{
Sarah Bettag ${ }^{1}$, Viyan S Kadhium² ${ }^{\circledR}$, Tarek Metwally ${ }^{3}$, Shernel Thomas ${ }^{4}$, Romesh P Nalliah ${ }^{5}$
}

\begin{abstract}
Background: In the United States, racial oral health disparities have shown to be as fundamental as democracy itself. Medicaid and the Affordable Care Act (ACA) have helped alleviate some of those disparities but have not eradicated them. The political structure of the United States affords great freedom to each state that develop regionally specific policies for their own state. Each state in the United States varies in terms of health policy, political position and resources. Therefore, the barriers they face and the most widely accepted solutions will vary from state to state. Due to the state-by-state variation, it is difficult to imagine a nationwide policy that could help.

The current analysis targets the four largest US states by population-California, Florida, New York, and Texas.

Aim and objective: The aim of our study is to understand and describe trends in oral health outcomes and the existence of any racial disparities in oral health by closely examining sociopolitical trends in the four largest states (by population)—California, Florida, New York, and Texas.

Materials and methods: Data from the Behavioral Risk Factor Surveillance System (BRFSS) were used to produce this report. We evaluated data between 1999 and 2016 for the four largest states in the United States (by population)—California, Florida, New York and Texas. Trends were identified in the oral health markers in adults aged 18 years and older. Responses were categorized according to participants' self-reported race and ethnicity.

Results: White adults in all four states were more likely to visit a dentist than black and Hispanic adults. White adults over the age of 65 years were less likely to have lost six or more teeth and also less likely to be edentulous. White adults aged 18-64 years were more likely to have retained all teeth than black and Hispanic adults.

Conclusion: Despite major improvements in oral health care within the United States, disparities still exist and vary from state to state and is not accorded with the same importance as general health care is. And that certain races/minority groups still experience disproportionate and unacceptable health care compared to their white counterparts.

Keywords: Barriers, Dental health, Health insurance, Oral health.

Journal of Oral Health and Community Dentistry (2021): 10.5005/jp-journals-10062-0104
\end{abstract}

\section{INTRODUCTION}

Despite major improvements in the oral health status of the United States (US) population as a whole, including increased oral health awareness and the emergence of associations between oral health and systemic disease, oral health disparities persist between various sectors of the US population. ${ }^{1,2}$ To more accurately monitor the population level oral health status, the 1999 Council of State and Territorial Epidemiologists (CSTE) identified four oral health markers: frequency of dental visits, frequency of dental cleanings, tooth loss, and community water fluoridation-markers which are still currently used to measure oral health improvement. ${ }^{3}$ This effort coincided with the release of the 2000 Surgeon General's Report, which heightened nationwide awareness of oral health disparities. The report concluded that observed oral health improvements were generally not evenly distributed among subpopulations. In fact, the burden of oral diseases and conditions was found to be disproportionately borne by individuals with low socioeconomic status-a result that mirrors other existing systemic health markers such as low birth weight and reduced life expectancy.

Oral health directly affects quality of life. ${ }^{4}$ Left untreated, oral health disease can progress to tooth loss, chronic infection and pain, and other adverse systemic health effects, which can in turn lead to lower self-esteem and loss of productivity and can harm job prospects for adults seeking work. ${ }^{5}$
${ }^{1-4}$ School of Dentistry, University of Michigan, Ann Arbor, Michigan, United States of America

${ }^{5}$ Department of Cariology, Restorative Sciences and Endodontics, School of Dentistry, University of Michigan, Ann Arbor, Michigan, United States of America

Corresponding Author: Viyan S Kadhium, School of Dentistry, University of Michigan, Ann Arbor, Michigan, United States of America, Phone: +909-287-4892, e-mail: vkadhium@umich.edu

How to cite this article: Bettag S, Kadhium VS, Metwally T, et al. Evaluating Race and Oral Health in the Four Largest States in United States of America. J Oral Health Comm Dent 2021;15(2):55-63.

Source of support: Nil

Conflict of interest: None

In 2010, the Affordable Care Act (ACA) was passed to provide healthcare to low-income adults, covering nearly 28 million lowincome nonelderly adults in 2014. Coverage of dental benefits is not mandatory under federal law, so states that choose to cover dental benefits generally provide limited coverage-often restricted to extractions or emergency services. ${ }^{5}$ It is noteworthy, too, that the Medicare program, which covers elderly adults and nonelderly adults with disabilities, provides essentially no dental benefits. ${ }^{5}$ While Medicaid coverage may increase the likelihood of individuals to visit the dentist, restrictions in dental benefits, access

() The Author(s). 2021 Open Access This article is distributed under the terms of the Creative Commons Attribution 4.0 International License (https://creativecommons. org/licenses/by-nc/4.0/), which permits unrestricted use, distribution, and non-commercial reproduction in any medium, provided you give appropriate credit to the original author(s) and the source, provide a link to the Creative Commons license, and indicate if changes were made. The Creative Commons Public Domain Dedication waiver (http://creativecommons.org/publicdomain/zero/1.0/) applies to the data made available in this article, unless otherwise stated. 
to providers, and limited dentist participation in Medicaid may still present as barriers to care.

Low socioeconomic status, minority status, and unemployment are associated with patterns of infrequent preventive dental care and, therefore, higher rates of dental disease. ${ }^{6}$ In 2009, the Centers for Disease Control and Prevention (CDC) reported that untreated tooth decay was twice as prevalent among those earning less than $100 \%$ Federal Poverty Level (FPL) compared to those earning above $200 \%$ FPL. ${ }^{3}$ Furthermore, adults without a high school diploma experience nearly three times the rate of untreated tooth decay and periodontal disease as their college-educated counterparts. ${ }^{2}$ Unfortunately, populations most likely to live in poverty in 2012 were black people (27\%) and Hispanic people (25.6\%), compared to only $9.7 \%$ of white people. ${ }^{7}$ Race is frequently omitted from discussions of oral disease-the American Dental Association's major study on oral health and well-being reported no difference in race and focused on household income. A recent study presented CDC data that highlighted a persistent gap in oral health outcomes between black and white populations that has persisted for 15 years. ${ }^{8}$ While this study drew attention to a concern, it did little to identify specific policy-related causes because US health policy is complex and varies from state to state. The current analysis targets the four largest US states by population-California, Florida, New York, and Texas - and attempts to understand the etiology of racial gaps in oral health outcomes. According to the US Census Bureau, these four states account for $33 \%$ of the US population. The current study is a trends analysis of changes in outcomes for the oral health markers identified by the CSTE from 1999-2016 in these four states.

\section{Materials and Methods}

Data from the Behavioral Risk Factor Surveillance System (BRFSS) were used to produce this report. The BRFSS is a system of healthrelated telephone surveys, managed by the $C D C$, that captures state data about US residents regarding their health-related risk behaviors, chronic health conditions, and use of preventive services. The BRFSS integrated the proposed surveillance questions into an ongoing annual telephone survey, conducted by state health departments. The BRFSS identifies four population level indicators of adult oral health:

- Dental Visit-Adults aged 18 years or older who visited a dentist or dental clinic during the last year.
- Teeth Cleaning-Adults aged 18 years or older who had their teeth professionally cleaned in the last year. Data for this indicator is not available after 2010.

- Complete Tooth Loss-Adults aged 65 years or older who have lost all natural teeth due to tooth decay or gum disease.

- Lost six or More Teeth-Adults aged 65 years or older who have lost six or more teeth due to tooth decay or gum disease.

Participant selection was randomized using random digit dialing techniques on both landlines and cell phones. ${ }^{9}$ BRFSS data were weighted using the iterative proportional fitting (IPF) or ranking method to reduce bias and to account for demographic and socioeconomic variables at a state level. ${ }^{10}$ The CDC curates the phone survey data and makes it available for researchers. We evaluated data between 1999 and 2016 for the four largest states in the United States (by population)—California, Florida, New York, and Texas. Trends were identified in the oral health markers in adults aged 18 years and older. Responses were categorized according to participants' self-reported race and ethnicity. University of Michigan Medical School's Committee on Human Studies provided institutional review board (IRB) exemption for this study (HUM00148281).

\section{Results}

In California, Florida, New York, and Texas, white adults saw a dentist more often than black and Hispanic adults. In all four states, compared to black and Hispanic adults, white adults over the age of 65 years were less likely to have lost six or more teeth and also less likely to be edentulous. Finally, in all four states, white adults aged 18-64 years were more likely to have retained all teeth than black and Hispanic adults.

\section{Visits to a Dentist or Dental Clinic among Adults Aged 18 Years and Older}

In California, the percentage of white adults responding positively to this question was steady between 1999 and 2016 at about $72 \%$ (Fig. 1). However, the percentage of black adults dropped from $66.0 \%$ in 1999 to $60.2 \%$ in 2016 (Fig. 1). The percentage of Hispanic adults was $57.0 \%$ in 1999 and $57.2 \%$ in 2016 (Fig. 1). The disparity between white adults and others became larger over the 17 years of the study.

In Florida, the percentage of white adults responding positively to this question was relatively stable but trending downward-in

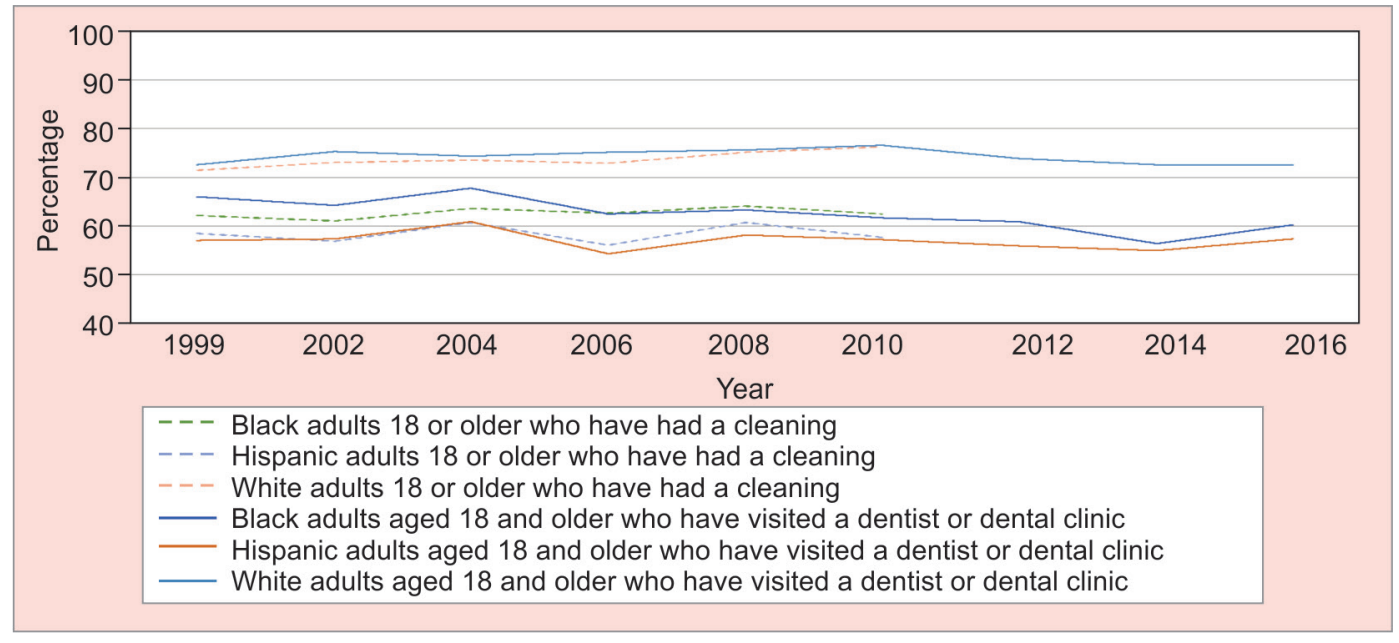

Fig. 1: California adults 18 and older who have had a cleaning and who have visited a dentist or dental clinic 
$1999,69.2 \%$ of white adults responded positively, but only $66.1 \%$ did so in 2016 (Fig. 2). The percentage of black adults visiting the dentist also declined from 65.5\% in 1999 to 57.2\% in 2016 (Fig. 2). However, the percentage of Hispanic adults in this category remained relatively stable with $60.8 \%$ in 1999 and $58.6 \%$ in 2016 (Fig. 2). The percentage of adults aged 18 years and over who attended a dentist in the previous year decreased in Florida between 1999 and 2016. The disparity between white and black populations increased over this period.

In New York, the percentage of white people aged 18 years and over who attended the dentist in the previous year was steady$72.7 \%$ in 1999 and $72.6 \%$ in 2016 (Fig. 3). The percentage of black adult attendance improved slightly-64.9\% in 1999 and 65.4\% in 2016 (Fig. 3). Unfortunately, the percentage of Hispanic adults dropped from $66.1 \%$ in 1999 to $59.6 \%$ in 2016 (Fig. 3). Though the gap between black adults and white adults improved; however, Hispanic adults had worse attendance in New York than both other racial groups.

In Texas, the percentage of white people responding positively to this question dropped slightly from $66.9 \%$ in 1999 to $64.7 \%$ in 2016 (Fig. 4). The percentage of black people responding positively increased from 58.3\% in 1999 to 63.9\% in 2016 (Fig. 4). Similarly, the percentage of Hispanic people responding positively increased from $45.0 \%$ in 1999 to $51.4 \%$ in 2016 (Fig. 4). In Texas, the disparity between white adults and others actually reduced during the period of the study.

\section{Adults Aged 18 Years or Older Who have had a Cleaning}

Among Californians, data about those aged 18 years and older who had a professional cleaning were collected between 1999 and 2010. The percentage of black adults who had a cleaning in 1999 was $62.2 \%$ and remained steady at $62.5 \%$ in 2010 (Fig. 1). The percentage of white adults improved from $71.4-76.2 \%$ while the percentage of Hispanic adults worsened from $58.4 \%$ in 1999 to $57.7 \%$ in 2010 (Fig. 1). White Californian adults had a larger percentage of the population obtaining preventive services in 1999, than both Hispanic and black adults 11 years later in 2010.

In Florida, the percentage of those aged 18 years and over who had had a cleaning decreased for all races. White adult cleanings decreased from 72.2-68.2\%; black adult cleanings fell dramatically from 63.8-52.9\%; and Hispanic adult cleanings also fell from $64.4-60.1 \%$ (Fig. 2). The rate of those receiving dental cleanings decreased across all races in Florida between 1999 and 2010 (Fig. 2), however, minority access to cleanings fell the most.

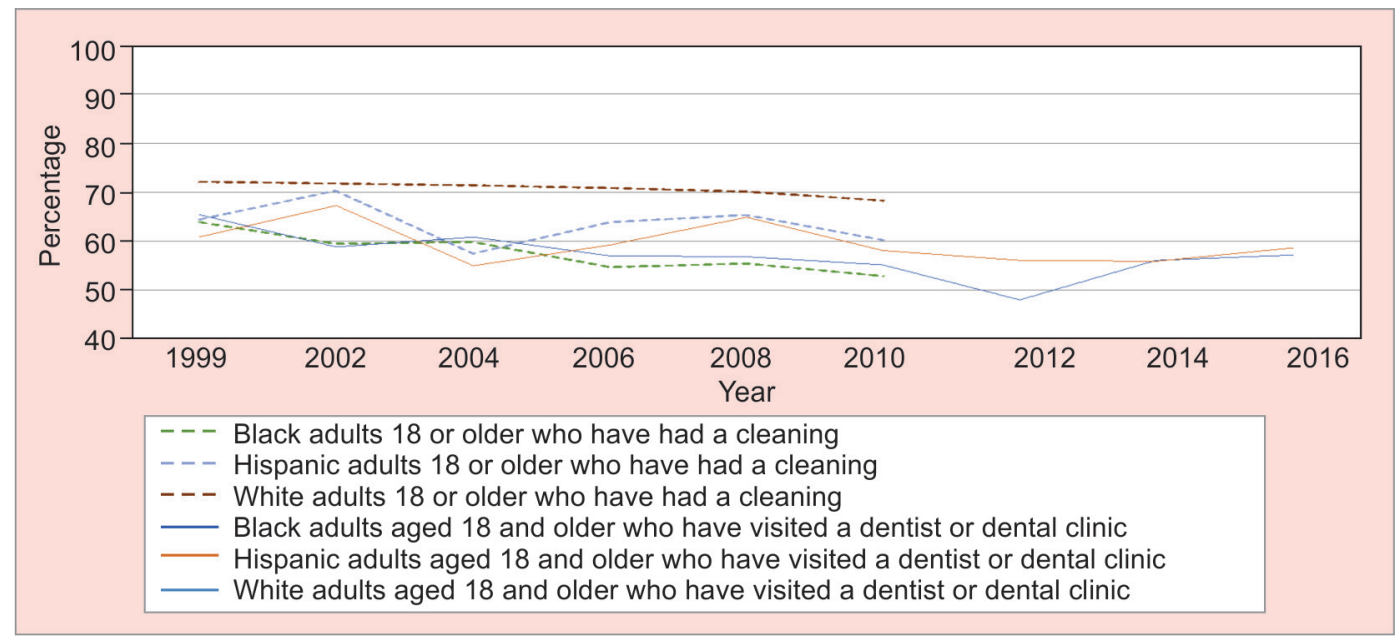

Fig. 2: Florida adults 18 and older who have had a cleaning and who have visited a dentist or dental clinic

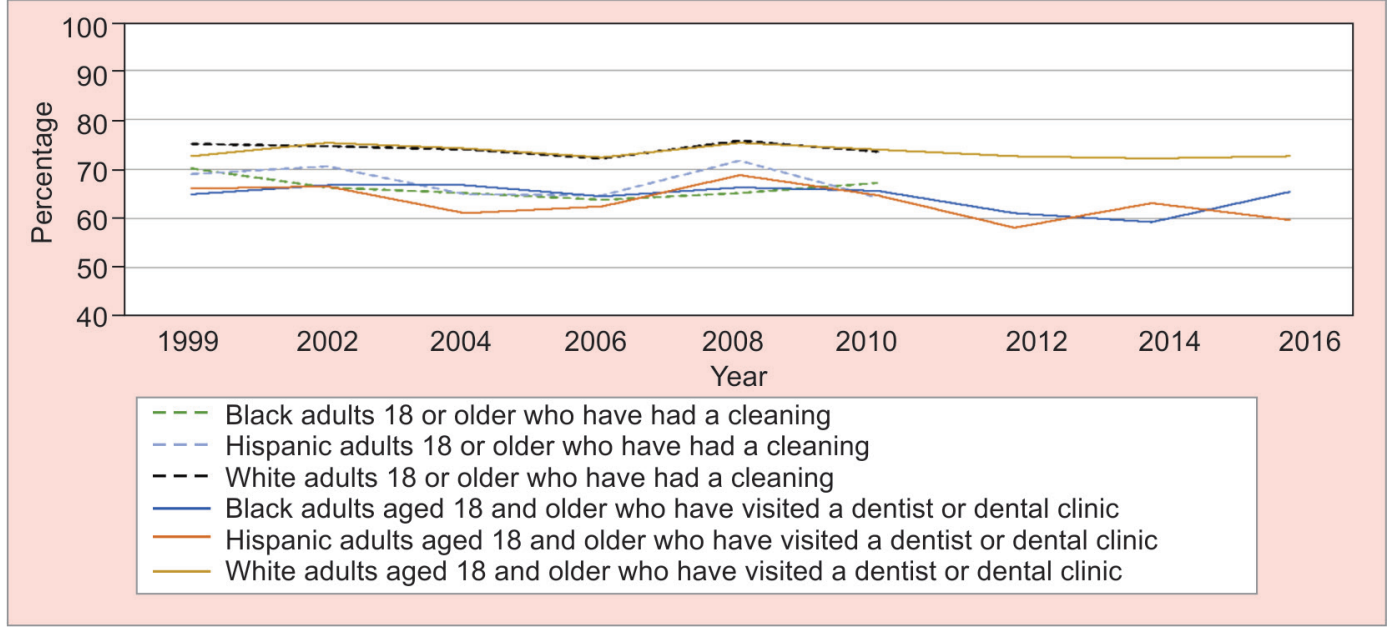

Fig. 3: New York adults 18 and older who have had a cleaning and who have visited a dentist or dental clinic 


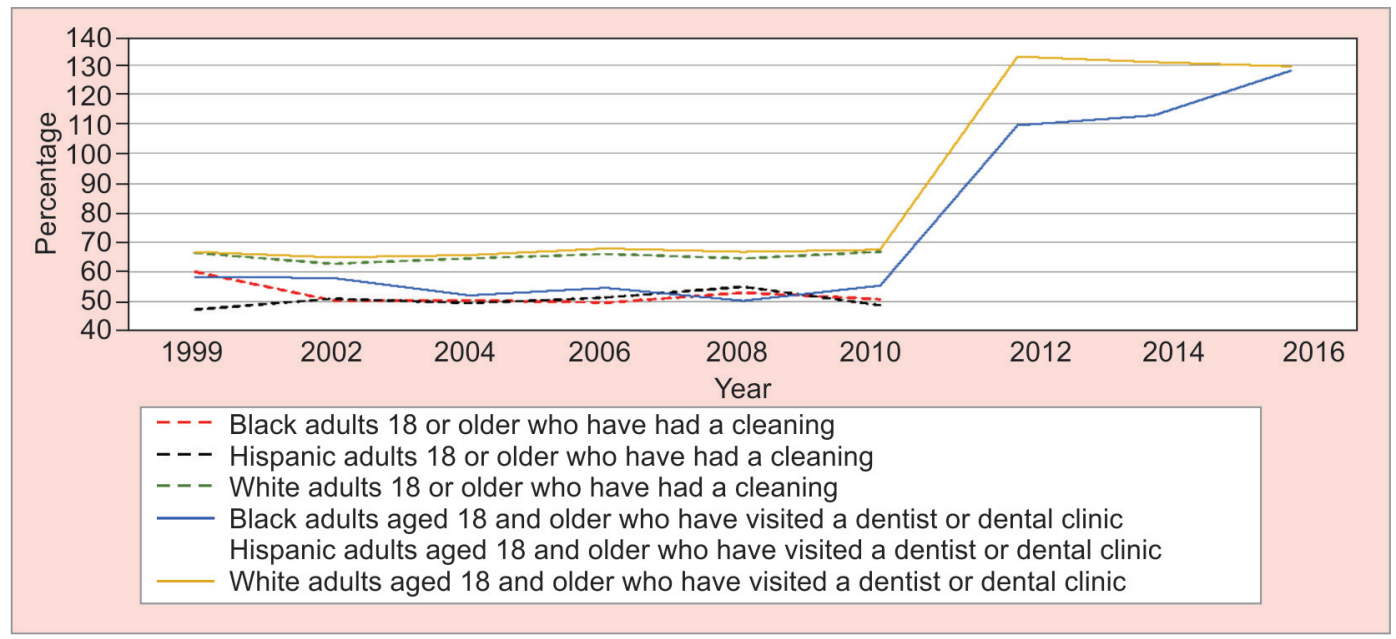

Fig. 4: Texas adults and older who have had a cleaning and who have visited a dentist or dental clinic

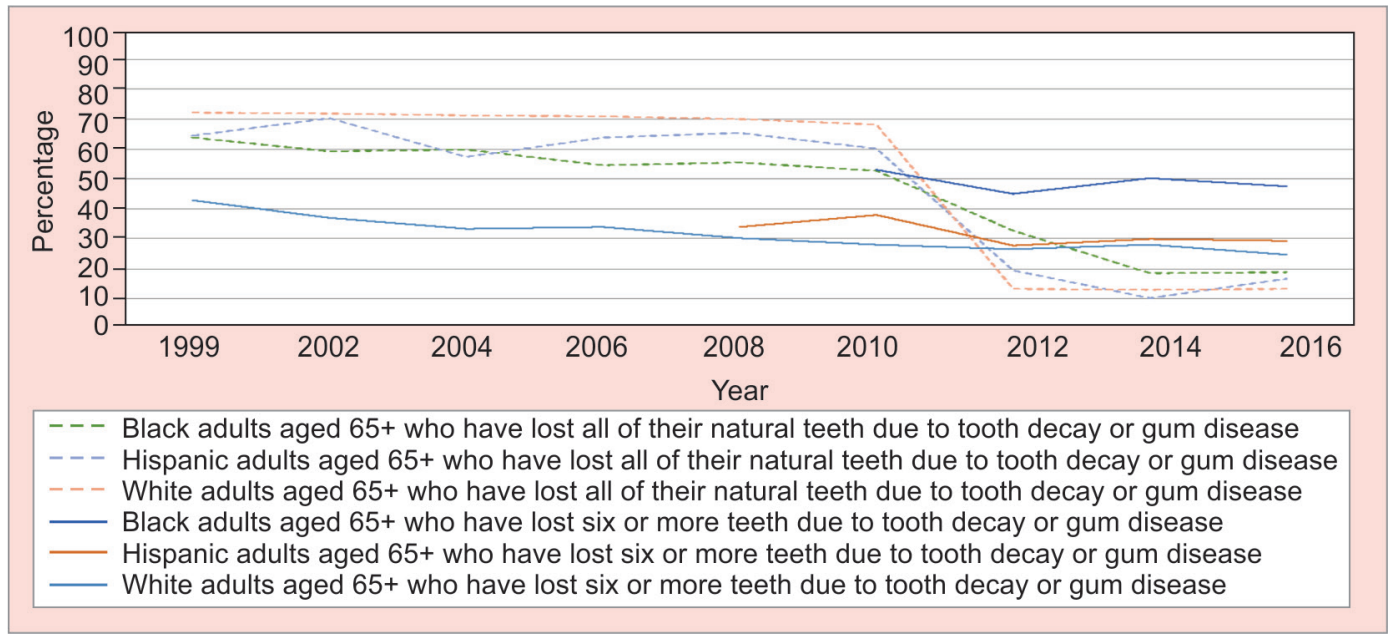

Fig. 5: California adults $65+$ who have lost all their natural teeth or who have lost six or more teeth due to tooth decay or gum disease

In New York, the percentage of cleanings for white adults decreased from 75.0-73.6\%; for black adults, this decreased from 70.1-67.1\%, and for Hispanic adults, this decreased from 69.1-64.2\% (Fig. 3). For all races, the rate of those receiving dental cleanings decreased in New York.

In Texas, rates for white and Hispanic adults were steady, 66.5-66.7\% and 47.5-48.9\%, respectively (Fig. 4). However, the situation worsened for black adults, who went from 59.9-50.9\% (Fig. 4). Black adults obtained cleanings less frequently than white and Hispanic adults in Texas.

\section{Six or More Teeth Lost among Adults Aged 65 Years and Older}

Interestingly, these data were only collected among white Californians between 1999 and 2008. In fact, data were not available across all races until as recently as 2012 . A total of $42.8 \%$ of white people aged 65 years or more in 1999 had lost six or more teeth, but this decreased to 24.5\% in 2016 (Fig. 5). In 2010 (first available data), $53.0 \%$ of geriatric black people had lost six or more teeth, and this improved slightly to $47.6 \%$ in 2016 (Fig. 5). However, a larger percentage of black geriatric people had lost six or more teeth in
2016 than white geriatric people in 1999 (Fig. 5). In 1999, a total of $34.0 \%$ of geriatric Hispanic Californians had lost six or more teeth, and this reduced to $29.2 \%$ in 2016 (Fig. 5).

In Florida, $49.1 \%$ of geriatric white people had lost six or more teeth in 1999, and this improved to $34.6 \%$ in 2016 (Fig. 6). A total of $62.8 \%$ of black geriatric people had lost six or more teeth in 2006 (first available data), and this improved to 51.5\% in 2016 (Fig. 6). Again, black geriatric people in 2016 were more likely to have lost six or more teeth than older whites in 1999. Thirty-one percent of Hispanic geriatric people had lost six or more teeth in 2004, and more (39.9\%) had lost six or more teeth in 2016, so Hispanic tooth retention for the geriatric populations actually worsened between 2004 and 2016 (Fig. 6).

In 1999, in New York, 49.5\% of white people in this group had lost six or more teeth, and this improved to $32.8 \%$ in 2016 (Fig. 7). However, $60.0 \%$ of black people in the population had lost six or more teeth in 2008 (first available data), and this improved to $49.9 \%$ in 2016 (Fig. 7). Black geriatric patients in 2016 in New York were worse off in this measure than white geriatric patients in 1999 (Fig. 7).

In Texas, $43.7 \%$ of white geriatric people in 1999 had lost six or more teeth and only $28.6 \%$ in 2016 (Fig. 8). Fifty percent of black people aged 65 years and older in 2008 had lost six or more teeth, 
and this improved slightly to 47\% in 2016 (Fig. 8). In 2002, 28.2\% of Hispanic adults in the same group answered positively to this question; however, in 2016, this actually worsened to $33.8 \%$ (Fig. 8). Between 2010 and 2016, the gap between the white population in this demographic and other races worsened (Fig. 8).

\section{All Teeth Lost among Adults Aged 65 Years and Older}

Edentulism data are only available from 2012, 2014, and 2016. In all four states studied, edentulism is the area of the greatest disparity between black and white people.

In California, the percentage of white people over the age of 65 years who reported being edentulous remained steady with $8.4 \%$ in 2012 to $8.2 \%$ in 2016 (Fig. 5). In 2014, 16.2\% of black people in the same category reported being edentulous, and this worsened in 2016 to $18.7 \%$. No data is available for 2012 or earlier for black populations (Fig. 5). For Hispanic Californians, 9.9\% reported being edentulous in 2012, and this worsened to $12.0 \%$ in 2016 (Fig. 5). White people had much lower rates of edentulism than all other races in California.

In Florida, the percentage of white geriatric people who reported being edentulous remained steady with 13.3\% in 2012 and $13.2 \%$ in 2016 (Fig. 6). Black geriatric people, however, suffered high rates of edentulism with $32.7 \%$ in 2012 and $18.9 \%$ in 2016 -an improved but nonetheless high percentage (Fig. 6). A total of $19.3 \%$ of the Hispanic geriatric population in 2012 reported edentulism, and $16.6 \%$ were edentulous in 2016 (Fig. 6).

In New York, some data are available from 1999-2016, and white geriatric edentulism rates improved from $24.5 \%$ in 1999 to $11.9 \%$ in 2016 (Fig. 7). Black geriatric edentulism increased from $14.3 \%$ in 2004 (the first-year data were available) to $17.1 \%$ in 2016 with a peak of $23.2 \%$ in 2008 during the global financial crisis (Fig. 7). Hispanic geriatric edentulism moved from $15.1 \%$ in 2008 (the first-year data were available) to 9.4\% in 2016 (Fig. 7). Hispanic respondents in 2016 actually had a better rate of edentulism than white respondents in 2016.

In Texas, $17 \%$ of white geriatric people reported being edentulous in 1999, and this fell to $11.7 \%$ in 2016 (Fig. 8). A total of $27.2 \%$ of black respondents reported edentulism in 2008 (the first-year data were available), and this fell to $22.3 \%$ in 2016 (Fig. 8). Hispanic geriatric edentulism fell from $17.1 \%$ in 1999 to $14.6 \%$ in 2016 (Fig. 8). Black respondents in Texas had a higher percentage of edentulism than all other races.

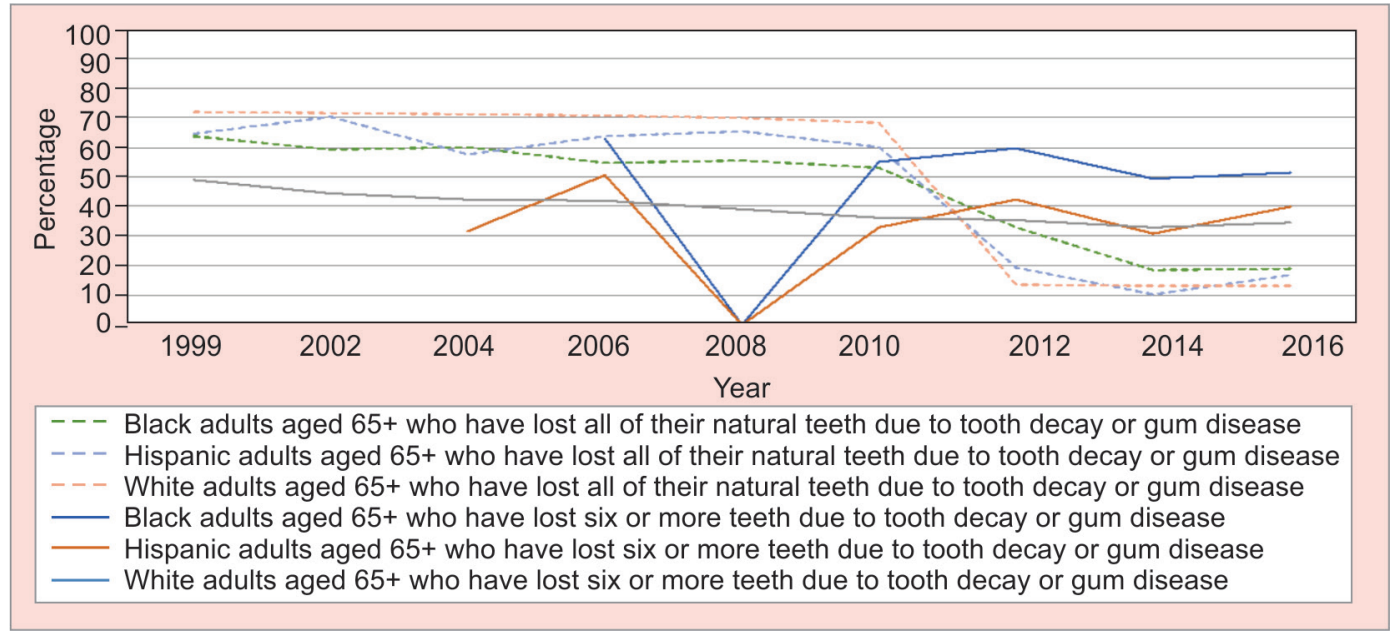

Fig. 6: Florida adults aged 65+ who have lost all of their natural teeth or who have lost six or more teeth due to tooth decay or gum disease

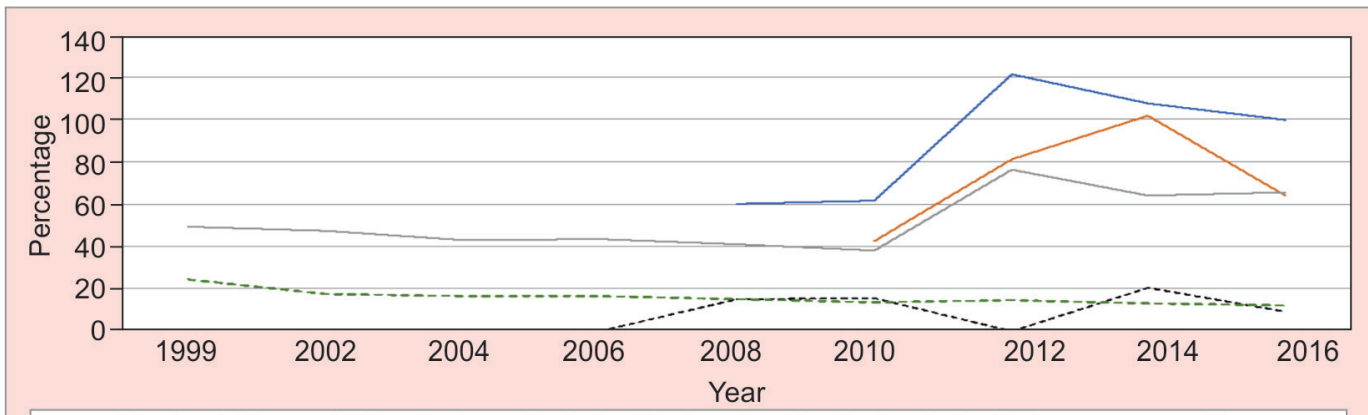

Black adults aged $65+$ who have lost all of their natural teeth due to tooth decay or gum disease

- - - Hispanic adults aged 65+ who have lost all of their natural teeth due to tooth decay or gum disease

- - - White adults aged 65+ who have lost all of their natural teeth due to tooth decay or gum disease

- Black adults aged 65+ who have lost six or more teeth due to tooth decay or gum disease

- Hispanic adults aged $65+$ who have lost six or more teeth due to tooth decay or gum disease White adults aged $65+$ who have lost six or more teeth due to tooth decay or gum disease

Fig. 7: New York adults aged 65+ who have lost all their natural teeth or who have lost six or more teeth due to tooth decay or gum disease 


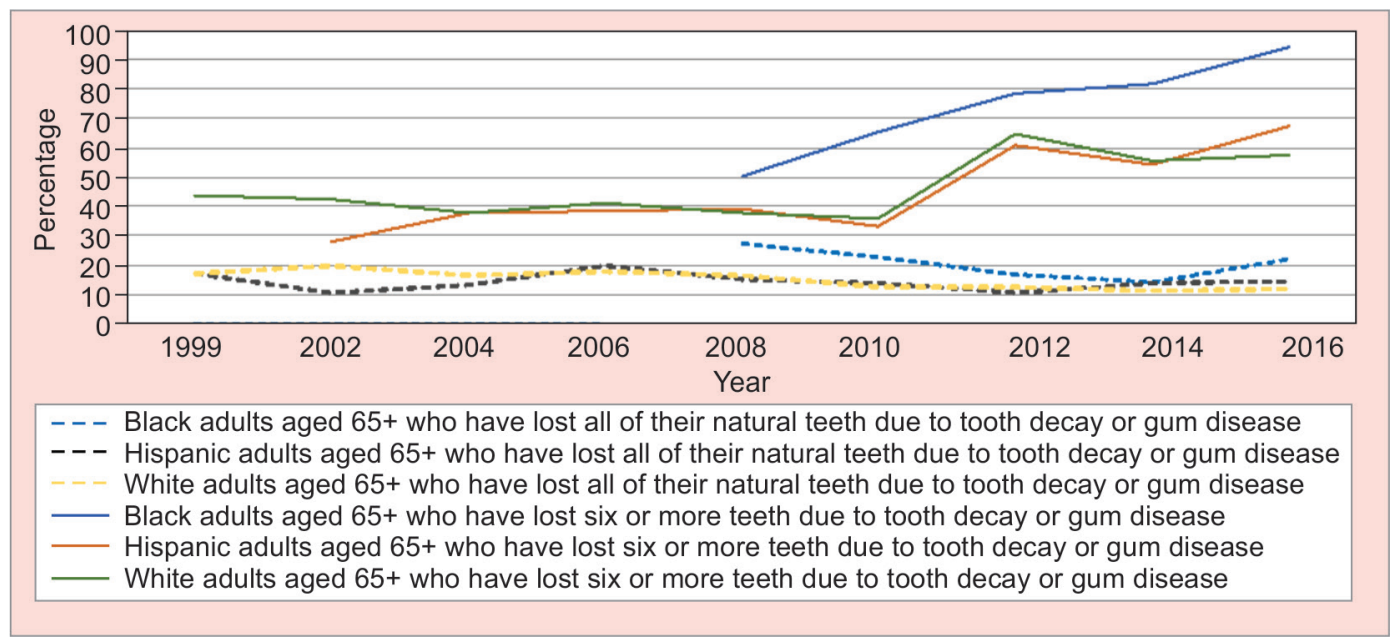

Fig. 8: Texas adults aged 65+ who have lost all of their natural teeth or who have lost six or more teeth due to tooth decay or gum disease

\section{Discussion}

England, Australia, and the Netherlands have federally operated health systems. However, in the United States, each state retains authority to decide on its own healthcare needs, and the federal government, while supplying some of the funds, limits its influence on each state's healthcare system. This is in contrast to the other governments mentioned where the federal government takes responsibility to administer the healthcare system for the entire country.

The four largest states have very different social, cultural, and economic patterns. In California, the disparity between white populations and others worsened during the 17 years of the study. Outcomes in the adult indicators of oral health were steady or improving among white adults; however, outcomes worsened during the study period for black and Hispanic adults.

\section{California}

In 2000, California had a population of 33.9 million people, of whom $57 \%$ were white, $7 \%$ black, and $26 \%$ Hispanic. By 2016 , California had grown in population to 39.2 million, of whom $39.1 \%$ were white, $37 \%$ were Hispanic, and only $5.5 \%$ were black. During the study period, there was a huge growth in the proportion of Hispanic and Asian residents (14.4\%) in California.

A democratic government was maintained throughout the study period, and their budget grew from $\$ 80.2$ billion in $1999-2000$ to $\$ 167.1$ billion in 2016-2017-over a 100\% increase. The overall Medi-Cal (Medicaid in California) expenditure per enrollee increased from $\$ 5,543$ in 2007-2008 to $\$ 7,839$ in 2017-2018-a 42\% increase. However, the number of enrollees in Medi-Cal had grown from 6.6 million-13.7 million in the same period, a 207\% increase. The resultant expenditure has almost tripled from $\$ 36.6$ billion in 2007-2008 to \$107.3 billion in 2017-2018.

Medi-Cal covered dental benefits (Denti-Cal) in 2007-2008. However, with the arrival of the global financial crisis, there was no coverage except emergencies and extractions from 2009-2013. This led to an increase in emergency room visits for dental problems with more than 1,800 additional emergency room (ER) visits per year. During this period, more than three million low-income adult enrollees had no dental coverage. On May 1, 2014, California restored partial dental benefits for adult enrollees in Medicaid, including preventive care, restorations, endodontic treatment for anterior teeth, and full dentures. Implementation of the ACA led to an increase of 5.6 million Medi-Cal enrollees between 2013 and 2017. However, in 2016, about 2.8 million Californians still did not have health insurance, and $65 \%$ of them were Latino. Today, the MediCal Dental Program covers a variety of dental services, including diagnostic, preventive, emergency, extractions, restorations, root canal therapy, crowns, periodontal care, and removable prostheses, for those who qualify. However, it should be noted that reimbursement rates for Medi-Cal Dental are among the lowest nationally which has driven the decline in dentist participation from $40 \%$ in 2003 to $24 \%$ in 2010 . Additionally, only about $25 \%$ of community health clinics in California offer dental services (around 245 clinics of the 857 licensed community clinics [2000-2016]). In this environment of constrained access to dental services, there is another major concern-that only $26 \%$ of Medi-Cal enrollees eligible for Dental benefits actually use them. Clearly, access to dental services has not comprehensively improved. While DentiCal covers a variety of procedures, reimbursement is one of the lowest in the country, and most eligible enrollees are not able to use their benefits.

Hispanic Californians suffered from poor oral health outcomes throughout the study which is in line with current evidence. A survey conducted by faculty at the University of Connecticut showed that $30 \%$ of Hispanic Americans believed their cavities would "go away on their own," and $45 \%$ of them lacked dental insurance. Moreover, $65 \%$ said they had "an oral health issue" in the past year. Poor oral health literacy has been shown to be a severe problem in this population, and because of their tremendous growth in population in California, there are implications for overall oral health of Californians. Research has also shown that Hispanic/Latino communities are less likely to seek dental care. While insurance and access are necessary, it is clear that culturally competent community education about oral health is also necessary. Health policies that enable Hispanic people-the fastest growing segment of the Californian population - to pursue and access dental services is critical. Failing to succeed in this initiative will lead to major increases of oral diseases in this state.

\section{Florida}

In 2000, Florida had a population of 15.9 million people, of whom $78 \%$ were white, $14.6 \%$ black, and $16.8 \%$ Hispanic. Florida's 
population grew to 20.8 million in 2018, of whom 53\% were white, $15 \%$ black, and $26 \%$ Hispanic. Florida has the third-largest Hispanic population in the United States, and during the study period, there was a tremendous growth in the proportion of Hispanics compared to that of whites.

Florida maintained a Republican government throughout the study period. The Florida's Medicaid budget in 1999-2000 was $\$ 48.7$ billion and decreased by 2016-2017 to a budget of $\$ 21.8$ billion. From 2002-2010, Medicaid only covered dental emergencies. In 2011, the coverage expanded limited coverage including exams, full and partial dentures, radiographs, and incision and drainage. ${ }^{11}$ Since the introduction of the ACA, Florida is one of the 19 states that chose not to expand Medicaid, leaving an estimated 3.8 million Floridians ( $20 \%$ of residents) without health insurance in 2013, according to the American Community Survey of the US Census Bureau. As a result, Floridian visits to a dentist decreased during the study period, dental cleanings decreased, and edentulism of six or more teeth increased for all groups.

One in four Floridians live in an area designated by the federal government as having a shortage of dentists, and 63 of 67 counties have at least one area that is short of a dental care provider. ${ }^{12}$ Most people without access to proper dental care live in rural areas. ${ }^{13}$ Because of Florida Medicaid's low payment rates, only $18 \%$ of dentists participated in Medicaid according to Floridians for Dental Access. This lack of Medicaid expansion as well as the poor distribution of dentists within the state could be major reasons why Florida residents are without health insurance, leaving the state with a high number of uninsured.

The Hispanic population in Florida will likely continue to grow. Unfortunately, there is a substantial wealth and income gap between whites and Hispanics in Florida, with a median white household wealth of over $\$ 100,000$ compared to Hispanic median household wealth of $\$ 6,000$, a 12 -fold gap. Furthermore, the majority of Hispanics and blacks living in Florida are young, with a median age of 35 and 32 years, while $90 \%$ of the population over 65 years of age are white, according to the US Census Bureau. As this 'young' Hispanic population continues to age and experience higher rates of poverty, oral health outcomes for these minority populations will worsen.

\section{New York}

In 2000, New York had a population of 18.9 million; $68 \%$ were white, $16 \%$ were black, and $15 \%$ were Hispanic. New York's population grew to 19.5 million by 2019 , of whom $70 \%$ were white; $19 \%$ were Hispanic; and $17.6 \%$ were black. During the study period, there was minimal fluctuation in the overall population with some growth in the Hispanic population.

A Republican governor served from 1999-2006, after which Democrat governors served from 2007 through 2017. The budget grew from $\$ 73$ billion in 1999-2000 to $\$ 155.6$ billion in 2016-2017more than doubling the budget in just 15 years. In 2006, nearly 2 million individuals were enrolled in the Medicaid managed care program, with all participating managed care plans offering dental services as part of their benefit packages. ${ }^{14}$ An additional program, Family Health Plus, provided comprehensive dental coverage for adults without health insurance whose income and resources disqualified them for Medicaid; however, this program was terminated in 2013 with the installment of the ACA Marketplace. As of 2012, adult Medicaid beneficiaries in New York (approximately $22 \%$ of the adult population or 14 million individuals) had an extensive dental benefit that included preventive services, minor and major restorative services, periodontal services, dentures, and oral surgery services. ${ }^{15}$ New York's Medicaid eligibility guidelines were already so generous that fewer than 286,000 of the 2 million enrollees were newly eligible as a result of the ACA's expansion of Medicaid. ${ }^{16}$ Federal financial assistance provided for the ACA expansion decreased the overall Medicaid expenditure per enrollee; ${ }^{17}$ however, New York's expenditure per enrollee continued to surpass Florida and California by almost $200 \%$ and that of Texas by over $26 \%{ }^{18}$

The New York state requires dental students to complete a 1-year postgraduate residency (PGY-1) to become certified to practice in the state of New York which may contribute to better access to care. The New York state has 45 general practice residencies and eight advanced education in general dentistry programs ${ }^{19}$ for a population of 19.5 million-this is a ratio of one residency for every 368,000 residents. ${ }^{20}$ Comparatively, the entire United States has 176 general practice residencies and 93 advanced education in general dentistry programs ${ }^{19}$ for a population of 330 million - a ratio of 1 residency for every 1.3 million residents. ${ }^{21}$

According to the American Immigration Council, one in five New Yorkers is an immigrant, and one in six is the child of an immigrant parent. Immigrants bring with them cultural behaviors, dietary practices, values, and beliefs that, in conjunction with exposure to new environmental and sociopolitical factors, likely influence their oral health. When controlling for socioeconomic factors and known oral health risk factors, researchers found the odds of having a higher level of tooth decay were $66 \%$ lower for immigrants who had been in the United States for more than 14 years than it was for those who had been in the United States for fewer than 5 years, ${ }^{22}$ showing that the longer immigrants were in the United States, the better they were able to overcome barriers to access to the oral health care system. Providing care for the large number of immigrants will require states like New York to improve access for this group.

\section{Texas}

In 2000, Texas' population was 20.9 million; 71\% were white, $11 \%$ black, and 32\% Hispanic. By 2016, Texas' population grew to 27.9 million, with a dramatic change in the proportion of whites and Hispanics. The proportion of white population declined to $41 \%$, the proportion of black population stayed roughly the same at $11 \%$, and the Hispanic population grew to $40 \%$.

Throughout the study period, Texas had a Republican government holding statewide office. In 1999-2000, its statewide budget was $\$ 49.5$ billion, which increased by $110 \%$ to $\$ 103$ billion in 2016-2017. Texas' Medicaid budget tripled from \$10 billion in 2000 to $\$ 29.4$ billion in $2017 .{ }^{23}$ However, the percentage of Texas' overall annual Medicaid budget allotted to dental care is less than $2 \% .{ }^{24}$

In 2000, 2.7 million Texans were enrolled in Medicaid, almost doubling to 4.5 million in $2017 .{ }^{25}$ Texas' Medicaid plans only provide adult dental coverage for emergencies. Like Florida, Texas also chose not to expand its Medicaid program under the ACA, and it has some of the most restrictive Medicaid eligibility criteria in the nation. Medicaid is available to adults whose income falls below $75 \%$ of the FPL (compared to the 138\% FPL in most states), with more lenient eligibility criteria for pregnant women and those with children. As a result, Texas has the highest percentage of citizens that are uninsured in the nation-17\% of Texans have no health insurance.

Furthermore, access to dental care is scarce. Almost $20 \%$ of counties lack even a single dentist and are generally concentrated in the panhandle, West Texas, and South Texas. ${ }^{26}$ Dentist enrollment in the Medicaid program is $10 \%$ lower than the national average; 
however, dentist participation in treating Medicaid patients may actually be much lower. According to survey participants, Texas reimbursement levels were $40-50 \%$ below insurance reimbursements. ${ }^{24}$ In 2007, due to a Supreme Court ruling, Texas increased dental reimbursement by $53 \%,{ }^{27}$ and our results show that visits by Hispanic patients to the dentist and adult cleanings increased in 2008 during our study period. Community Health Centers (CHCs) and Federally Qualified Health Centers (FQHCs) play a large role in providing dental care in Texas. In 2007, Texas CHCs employed 110 dentists who logged more than 285,000 patient visits. ${ }^{26}$

In 2014, the three poorest metropolitan areas in the United States were in Texas. Poverty rates are strongly linked to race and ethnicity, and in Texas, the number of blacks and Hispanics living in poverty was almost triple the number of whites in 2013. Extensive research has linked poverty and poor health outcomes. Because of Texas' stringent Medicaid eligibility requirements as well as large percentages of minority populations experiencing poverty, it is likely that the existing poor oral health outcomes will continue to exacerbate without an intervention.

\section{Conclusion}

Medicaid is the primary source of dental coverage for low-income families, the elderly, and disabled people in the United States; however, Medicaid accessibility and coverage varies by state, and even by year. Despite continuing advancement in the diagnosis, treatment, and management of disease, oral health disparities persist, as evidenced by higher rates of edentulism and lower rates of regular cleanings and dental visits in minority populations. New York's consistent Medicaid coverage expanded dental benefits, and increased expenditure-perenrollee improved dental care for minorities compared to California, Florida, and Texas, who did not see the same steady improvements in black and Hispanic geriatric edentulism nor improvements in the number of black people who visited a dentist. The consistency of Medicaid coverage demonstrated more of an effect on minority patients' oral health than even the political party of the state's governor. Texas and Florida experienced tremendous growth in the Hispanic population; however, these states saw a decrease in dental visits and cleanings among minorities; interestingly, they were still able to improve some geriatric edentulism rates.

Though minority health outcomes are generally poorer than those of whites, enacting state-wide and national health policies can significantly improve accessibility to care and drive improvements in health equality. However, the elimination of oral health disparities cannot be achieved without addressing micro-level factors such as the cultural gap and between providers and minority populations who lack access to care. Moving toward equitable access to dental care will require collaboration between legislatures, dentists, and community members to remove the cultural, financial, and systemic barriers to care.

\section{ORCID}

Viyan S Kadhium @ https://orcid.org/0000-0002-4473-9582

\section{References}

1. U.S. Department of Health and Human Services. Oral health in America: a report of the surgeon general. 2000. Available from: https://www.nidcr.nih.gov/sites/default/files/2017-10/ hck1ocv.\%40www.surgeon.fullrpt.pdf.
2. Disparities in oral health. Centers for Disease Control and Prevention; 2019. Available from: https://www.cdc.gov/oralhealth/oral_health_ disparities/index.htm.

3. Malvitz DM, Barker LK, Phipps KR. Development and status of the National Oral Health Surveillance System. Prev Chronic Dis 2009;6(2):1-7. PMID: 19289009.

4. Bennadi D, Reddy CVK. Oral health related quality of life. J Int Soc Prev Community Dent 2013;3(1):1-6. DOI: 10.4103/2231-0762.115700.

5. Access to dental care in Medicaid: spotlight on nonelderly adults. Kaiser Family Foundation; 2016. Available from: https://www.kff.org/ medicaid/issue-brief/access-to-dental-care-in-medicaid-spotlighton-nonelderly-adults/.

6. Drury TF, Garcia I, Adesanya M. Socioeconomic disparities in adult oral health in the United States. Ann N Y Acad Sci 1999;896(1):322-324. DOI: $10.1111 /$ j.1749-6632.1999.tb08129.x.

7. Social determinants of health. Healthy people 2020;2020. Available from: https://www.healthypeople.gov/2020/topics-objectives/topic/ social-determinants-of-health/national-snapshot.

8. Nalliah RP, Virun V, Dhaliwal G, et al. Fifteen-year gap between oral health of blacks and whites in the USA. J Investig Clin Dent 2019;10(3):e12415. DOI: 10.1111/jicd.12415.

9. Survey Data \& Documentation. Centers for Disease Control and Prevention; 2020. Available from: https://www.cdc.gov/brfss/ data_documentation/index.htm.

10. Behavioral Risk Factor Surveillance System. Atlanta (GA): Centers for Disease Control and Prevention. 2013. Available from: https:// www.cdc.gov/brfss/annual_data/2012/pdf/Compare_2012.pdf.

11. Florida Medicaid's covered services and HCBS waivers: dental services. Agency for Health Care Administration; 2020. Available from: https://ahca.myflorida.com/medicaid/Policy_and_Quality/Policy/ behavioral_health_coverage/primary_care_policy/Dental.shtml.

12. HPSA Find-HRSA data. Health Resources \& Service Administration; 2019. Available from: https://data.hrsa.gov/tools/shortage-area/ hpsa-find.

13. Logan HL, Catalanotto F, Guo Y, et al. Barriers to Medicaid participation among Florida dentists. J Health Care Poor Underserved 2015;26(1):154-167. DOI: 10.1353/hpu.2015.0000.

14. Bureau of Dental Health. The impact of oral disease in New York state. 2006. Available from: https://www.health.ny.gov/prevention/dental/ docs/impact_of_oral_disease.pdf.

15. Surdu S, Langelier M, Moore J. Utilization of oral health services by medicaid-insured adults in New York, 2012-2013. Oral Health Workforce Research Center, Center for Health Workforce Studies, School of Public Health, SUNY Albany; 2016. Available from: http:// www. oralhealthworkforce.org/wp-content/uploads/2016/12/ OHWRC_ Utilization_Oral_Health_Services_Medicaid_Adults_NY_2016.pdf.

16. Norris L. New York and the ACA's Medicaid expansion. Health Insurance; 2018. Available from: https://www.healthinsurance.org/ new-york-medicaid/

17. NHE Fact Sheet. Centers for Medicare \& Medicaid Services; 2020. Available from: https://www.cms.gov/Research-Statistics-Data-andSystems/Statistics-Trends-and-Reports/NationalHealthExpendData/ NHE-Fact-Sheet.

18. Citizens Budget Commission. Medicaid in New York. 2006. Available from: http://www.cbcny.org/sites/default/files/reportsummary_ medicaid_04202006.pdf.

19. Search for Dental Programs. American Dental Association; 2020. Available from: https://www.ada.org/en/coda/find-a-program/searchdental-programs\#t=us\&sort=\%40codastatecitysort\%20ascending.

20. United States Census Bureau. QuickFacts: New York; 2020. Available from: https://www.census.gov/quickfacts/NY.

21. Population Clock. United States Census Bureau; 2020. Available from https://www.census.gov/popclock/.

22. Cruz GD, Chen $Y$, Salazar CR, et al. The association of immigration and acculturation attributes with oral health among immigrants in New York city. Am J Public Health 2009;99(Suppl. 2):S474-S480. DOI: 10.2105/AJPH.2008.149799. 
23. Smith C, Young CE, Jessee $G$, et al. Texas Medicaid and CHIP in perspective. Texas Health and Human Services Commission; 2017. Available from: https://hhs.texas.gov/sites/default/files/documents/ laws-regulations/reports-presentations/2017/medicaid-chipperspective-11th-edition/11th-edition-complete.pdf.

24. Blackwelder A, Shulman JD. Texas dentists' attitudes toward the Dental Medicaid program. Pediatr Dent 2007;29(1):40-46. PMID: 18041511.
25. Dunkelberg A. Texas Medicaid Data. Every Texan; 2017. Available from https://everytexan.org/images/2017_06_27_CPPP_Texas_Medicaid_ Data.pdf.

26. Texas Dental Association. Building better oral health: a dental home for all Texans. Tex Dent J 2008;Suppl:1-56. PMID: 19363885.

27. Nasseh K, Vujici M. The impact of Medicaid reform on children's dental care utilization in Connecticut, Maryland, and Texas. Health Serv Res 2015;50(4):1236-1249. DOI: 10.1111/1475-6773.12265. 